\title{
ARTE E CONHECIMENTO: O PENSAMENTO MODERNO OCIDENTAL E A RAZÃO SEPARADA
}

\section{ART AND KNOWLEDGE: THE MODERN WESTERN THINKING AND SEPARATE REASON}

\author{
Carlos Weiner Mariano de Souza ${ }^{1}$
}

\section{RESUMO}

O termo sentir aplicado ao conhecimento sempre causou estranheza no ambiente educativo, uma vez que em nosso processo de formação aprende-se a separar, a distinguir entre o mental e o físico, dando prevalência ao primeiro. A busca dos elementos epistemológicos que calcaram essa separação é o que nos impulsiona à reflexão neste artigo, que se guiou pela recuperação do pensamento de alguns dos autores que foram mais destacados no percurso de consolidação do pensamento moderno ocidental. Em termos de apontamentos finais, destacamos que o paradigma moderno trouxe certezas construídas sob a negação da dimensão sensível para educação do homem e relegou à arte um papel secundário no processo de formação dos sujeitos. Em contraponto, é no emaranhado de desafios educativos que são colocados no contemporâneo, sobretudo, para os que trabalham com crianças e adolescentes, que compreendemos a relevância do papel da arte, do fazer artístico (expressão poética) e da experiência estética, bem como suas possibilidades de conduzir os sujeitos à interação com conteúdos de sua própria cultura.

Palavras-chave: Arte; educação; conhecimento; modernidade.

\begin{abstract}
The term applied to knowledge always feel strange caused the educational environment, since in our training process learns to separate, to distinguish between the mental and physical, giving precedence to the first. The search for the epistemological elements that trampled this separation is what drives us to reflect in this article, which was guided by the thought of recovering some of the authors who were most prominent in the path of consolidation of the modern Western thinking. In terms of end notes, we emphasize that the modern paradigm has brought certainty built on the denial of the sensitive dimension to the education of male and relegated to the art a secondary role in the formation of subjects. In contrast, is the tangle of educational challenges that are placed in the contemporary, especially for those working with children and adolescents, we understand the important role of art, artistic (poetic expression) and the aesthetic experience, as well as their possibilities of bringing the subject to interact with content from their own culture.
\end{abstract}

Key Words: Art; education; knowledge; modernity.

1 Artista educador, Mestrando em Artes Visuais na Escola de Comunicação e Artes na Universidade de São Paulo (USP), especialista em Arte e cultura no século XVIII (UFOP) e em Música no século XX Computação sônica (UFU). Graduado em Artes Plásticas pela Universidade Federal de Uberlândia. E-mail: caweca@terra.com.br.

Divers@Revista Eletrônica Interdisciplinar/Matinhos/Vol.5, n.1/p.1-92|/jan./jun.2012 
Introdução

O termo sentir aplicado ao conhecimento sempre causou estranheza no ambiente educativo, uma vez que em nosso processo de formação aprende-se a separar, a distinguir entre o mental e o físico, dando prevalência ao primeiro. Enquanto termos como sentimento, imaginação e criação parecem ter um lugar natural nas aulas de arte, a palavra razão, aplicada às demais áreas do saber continua assumindo os contornos do entendimento, da inteligência.

Partimos aqui do pressuposto de que os processos que envolvem o aprendizado do mundo, sob o encargo da educação, dependem para sua efetividade da articulação equilibrada entre as formas de perceber e construir juízos sobre o que se percebe. Tal convicção emerge a partir de uma prática e visão de mundo que entende a dimensão sensível e as ações educativas em arte como imprescindíveis no processo de construção do conhecimento e para o desenvolvimento humano.

Para Richter (2006)

A dimensão sensível que caracteriza o ser humano ao encontrar sua especificidade no sentir, imaginar, perceber, fazer, significar, portanto ao envolver todo o sistema de afetos que organiza e redimensiona sensações corporais e nos conecta intelectualmente com os outros e com o mundo através de nossas possibilidades criadoras e inventivas (RICHTER, 2006, p.01)

Nesse sentido, é interessante resgatar em Read (1986) o sentido coeso da fusão entre arte e educação. Na obra desse autor os dois conceitos são fundidos de tal forma que, ao falar de arte se refere a um processo educacional, portanto, de crescimento e ao falar de educação se refere a um processo artístico, no sentido de compreendê-lo como um processo de autocriação. Ambos, crescimento e autocriação, apontam para a completude e a complexidade do humano.

A perspectiva de Read aponta para abordagens que atuam no sentido de problematizar e de colocar alternativas ao caminho que se tornou hegemônico na sociedade moderna. Traz a necessidade de um olhar crítico sobre as formas como o sistema educativo da modernidade, cuja gênese se deu sob o anseio do progresso, conduziu os processos que envolvem a formação do homem no sentido da instrumentalização do saber e da supressão da dimensão estético/poética que envolve a construção do conhecimento.

Todavia, o que se observa no campo prático da construção dos saberes, mesmo no contexto do contemporâneo, é a dicotomização desses elementos. É exatamente em busca dos

Divers@Revista Eletrônica Interdisciplinar/Matinhos/ Vol.5,n.1/p.1-92//jan./jun.2012 
elementos epistemológicos que calcaram essa separação que nos impulsiona à reflexão neste artigo, que se guiou pela recuperação do pensamento de alguns dos autores que foram mais destacados no percurso de consolidação do pensamento moderno ocidental.

\section{Construção do conhecimento no debate moderno}

A dimensão educativa da experiência estético/poética propiciada na relação com a arte e sua importância no processo de conhecimento humano recoloca um debate que esteve presente na formação do pensamento moderno.

A historiografia oficial, no que tange à matriz do pensamento ocidental, pontua o século XV como período referencial de transformações na vida e na concepção de mundo dos povos europeus. Na base do pensamento moderno está o Humanismo, que se tornou a força de uma expressão de mudança cultural cuja ênfase está na razão humana como fonte para a descoberta das verdades, que estão colocadas no mundo natural e que requerem interpretação lógica. Conforme Lara (1986, p. 26),

[...] os humanistas são homens que se dedicam ao estudo dos clássicos gregos e latinos, que defendem o valor da razão humana para descobrir a verdade; que exaltam a natureza física, a vida aqui na terra.

O antropocentrismo representou a dimensão mais contundente do Humanismo. No decorrer dos séculos XIV, XV e XVI, o homem pode ser visto como criador mediante a natureza, da qual se percebe como distinto. Ao mesmo tempo em que se libertava da admiração, adoração, obediência frente ao ambiente natural, o homem passava a cultivar novos valores relacionados à individualidade, liberdade, criatividade, participação e enriquecimento.

A partir dessa proposição clara de compreensão e domínio da natureza, os séculos XV e XVI revelaram a abundância de elaborações teóricas baseadas na racionalidade, na lei natural e na liberdade do homem (LARA, 1986). Essa orientação aparece na arte como um aspecto da atitude científica diante da natureza, como nos afirma Osborne (1968), ao proceder à análise sobre a estética renascentista.

É um hábito mental tratar a natureza como algo externo ao homem e separado dele, algo para ser estudado e observado com objetividade científica, senhoreado e aproveitado pelo homem, algo capaz de inspirar reações emocionais, ou de ser espelhado, lisonjeado ou melhorado pela arte (OSBORNE, 1968, p. 118).

Divers@Revista Eletrônica Interdisciplinar/Matinhos/Vol.5, n.1/p.1-92|/jan./jun.2012 
Foi neste período que os sistemas filosóficos modernos começaram a se estruturar. Processo que implicou na abolição de ideias que até então vinham aprisionando a educação e a cultura ao conceito de homem servil, oprimido pela pobreza e pelos dogmas da religião. A consolidação das duas correntes filosóficas mais importantes para formação do ideário moderno, o racionalismo e o empirismo ${ }^{2}$, deu a tônica do debate tanto ao campo da arte, quanto às pretensões de uma nova ciência a partir do século XVII. O racionalismo afirmava a razão como única faculdade de proporcionar o conhecimento adequado da realidade. Defendia sua confiança na capacidade do pensamento matemático, símbolo da autonomia da razão, para interpretar adequadamente o mundo. No caminho contrário, o empirismo refutou a existência das ideias inatas. Postulava que a mente é, usando uma expressão coloquial, uma folha de papel em branco, cujo material que nela escreve as impressões, provém da experiência (ABRÃO, 1999).

A obra de René Descartes representou um marco essencial do racionalismo moderno, a partir da aplicação sistemática da dúvida metódica ${ }^{3}$. Segundo Lara (1986, p. 36) "o que realmente aparece de distinto em relação ao pensamento medieval é o privilégio do sujeito". O homem torna-se sujeito do conhecimento, intérprete e revelador, mas nunca o criador. Este elemento do subjetivismo é de fato inovador na obra de Descartes e será crucial para fundar as bases do pensamento moderno. O racionalismo, a partir deste prisma, não rompeu com a transcendência, o que permite compreender uma faceta idealista da obra de Descartes.

Segundo Osborne (1968), houve nesse período "uma estreita relação entre o interesse nascente pela ciência empírica e o estudo das artes” (p.128). A arte compreendida como mimese, imitação da natureza, teve nas ciências empíricas seu amparo e orientação. A atividade artística, fundamentalmente a pintura e a escultura, era considerada um ramo do conhecimento e o artista, em oposição ao artesão, começou a adquirir um novo status social, assumindo a condição de intelectual e cavalheiro.

Segundo Bourdieu (2007), apesar da vida intelectual e artística permanecer sob a tutela da aristocracia e da igreja, atendendo às suas demandas éticas e estéticas, teve início

2 Para o racionalismo existe um mundo de essências, verdades puras, que dá sentido ao mundo da experiência. O empirismo, por sua vez, considera o mundo dos fatos, estes sim capazes de colocar limites ao conhecimento. A doutrina empirista teve seu marco na obra do inglês John Locke, no século XVII. Já o racionalismo foi introduzido na filosofia moderna por René Descartes (1596-1650), Spinoza (1632-1677) e Leibniz (1646-1716) (ABRÃO, 1999).

3 A dúvida metódica é um instrumento metodológico, a partir da qual Descartes buscou chegar à prova de existência de verdades absolutas, necessárias ao reconhecimento do universal (SANTOS, 1962).

Divers@ Revista Eletrônica Interdisciplinar/Matinhos/Vol.5, n.1/p.1-92|/jan./jun.2012 
uma progressiva liberação tanto do ponto de vista econômico, quanto social. Esse processo de autonomização da produção intelectual e artística havia iniciado em Florença no século XV na busca pela afirmação de uma legitimidade propriamente artística. A partir do século XVIII as instâncias de autonomização do campo da arte começaram a se multiplicar através das academias e dos salões. No entanto, do ponto de vista estético, a beleza artística se mantinha na condição de inferioridade em relação à beleza natural e sendo avaliada a partir dos referenciais proporcionados pela natureza.

Nas premissas da cultura humanista estiveram a possibilidade, a urgência e a necessidade de levar a força da racionalidade e da natureza humana às últimas consequências. Ao mesmo tempo, houve a gradativa substituição da razão pelo sentimento como critério fundamental para avaliação dos objetos da arte. Todavia torna-se relevante destacar, segundo Nunes (1999), que essa dinâmica se apresenta em uma época em que a beleza e a arte eram marginalizadas e tratadas como irrelevantes pela reflexão filosófica, sendo levadas em conta apenas por seus aspectos racionais.

Nesse contexto, nasceu a Estética, que passou a ser definida como Filosofia da Arte por Alexander Baumgarten, tendo a apreciação da beleza como seu tema fundamental. A arte passa a ser concebida como produto da atividade humana, cuja finalidade é produzir de forma artificial os aspectos inerentes à beleza universal. O Belo, ainda a partir da definição de Baumgarten, se apresenta como a perfeição do conhecimento sensível, colocando-o como domínio da sensibilidade relacionado com a percepção e a imaginação. A beleza e seu reflexo nas artes, no entanto, se apresentavam como um conhecimento inferior ao racional. Apenas este último seria dotado de clareza e tendência para a verdade (NUNES, 1999).

Tal proposição foi impulsionadora da estética de Kant no que se refere à autonomia do Belo, questão tratada em sua Crítica do Juízo (1993). A experiência estética não aparece na obra de Kant como uma cognição inferior e tampouco, como processo que visa ao conhecimento, e sim como uma experiência que começa e termina na satisfação que os objetos provocam na subjetividade (NUNES, 1999).

São três as modalidades de experiência para Kant (1993), a cognitiva, referente ao conhecimento intelectual; a prática, relativa aos fins morais que o homem procura na vida, e a experiência estética, que se fundamenta na intuição, no sentimento dos objetos que nos dão prazer, uma atitude contemplativa de caráter desinteressado. Ideia que nutriu o pensamento

Divers@Revista Eletrônica Interdisciplinar/Matinhos/Vol.5,n.1/p.1-92//jan./jun.2012 
moderno e se apresenta de forma bastante contundente ainda no contexto contemporâneo, inclusive nas ações educativas.

A ideia kantiana segundo a qual "a faculdade de ajuizamento de um objeto ou de um modo de representação mediante uma complacência ou uma descomplacência independente de todo interesse" (KANT, 1993, p.183) assumiu um lugar destacado no campo da arte. Dela deriva a proposição de que a experiência estética, particularmente com a arte, constitui um prazer desinteressado.

Gadamer (2005), ao tratar dessa questão, discorre sobre as consequências negativas da convicção kantiana, principalmente no contexto atual, ao afirmar que o modo de ser do próprio objeto de arte "ganha o seu verdadeiro ser ao transformar-se em experiência que transforma" (p. 154). Para este autor, a arte não provoca apenas um prazer subjetivo que se encerra nele mesmo, mas nos oferece a possibilidade de uma nova compreensão. A experiência com a arte, seja no processo de configurar formas artistas, ou na fruição das mesmas, é capaz de nos mostrar algo sobre nós mesmos e transformar a maneira como nos relacionarmos com o meio em que vivemos.

Segundo Osborne (1968, p.141), “o conceito de prazer desinteressado, no século XVIII, tinha seu correspondente na noção de Belas-Artes" e foi se tornando progressivamente acentuado. Sendo assim, a relação de fruição deixou de estar ligada à ideia de finalidade da arte, para se ligar a uma classe de artefatos fabricados para contemplação e o prazer estético. Orientação que contribuiu para um gradativo desligamento da arte em relação ao seu propósito moral na sociedade.

Zatti (2007) destaca que na obra de Kant, o conhecimento humano é incapaz de ultrapassar o mundo sensível, o mundo dos fenômenos, concepção teórica que promoveu e sustentou a ruptura entre mundo sensível e mundo inteligível, entre a arte e o mundo vivido.

\footnotetext{
Embora Kant tenha se referido à educação como uma arte, a educação estética, em suas obras, não é devidamente acionada. Seu "idealismo" concebe a educação como arte da humanidade a ser aperfeiçoada por várias gerações e na prática educativa a subordinação ao dever, ao formalismo do imperativo categórico, não deixa o espaço devido para a ação estética (ZATTI, 2007, p.73).
}

Em sentido diverso a esse trilhado por Kant, esteve a perspectiva teórica de Hume, no que se refere à reflexão sobre as faculdades sensíveis e a razão humana. Em suas conclusões, o homem aparece mais como um ser prático e sensitivo que propriamente racional. Desconsiderava qualquer conhecimento que não tivesse origem na percepção, em impressões 
oriundas do contato sensível e dos sentimentos. Para ele, as ideias são cópias pioradas das impressões, dado que jamais serão capazes de alcançar o real sentimento ou percepção da vivência de algo. O autor caminha, em seu percurso analítico, para uma perspectiva que é cética em relação à razão científica (HUME, 1999). Em Hume a razão aparece como mendiga da verdade e

[...] O costume é, pois, o grande guia da vida humana. É o único princípio que torna útil nossa experiência e nos faz esperar, no futuro, uma série de eventos semelhantes aqueles que apareceram no passado. Sem a influência do costume, ignoraríamos completamente toda questão de fato que está fora do alcance dos dados imediatos da memória e dos sentidos (HUME, 1999, p.63).

Para o autor, sem a autoridade do costume não seria possível estabelecer qualquer relação com o mundo, já que é sobre a influência dele que vivemos. Destaca-o como uma espécie de força subjetiva que define a constância necessária em todos os acontecimentos da vida. Um fenômeno que emerge da multiplicidade de vivências semelhantes no espaço e no tempo, nas relações duráveis que se organizam por meio da cultura.

$\mathrm{Na}$ obra de Hume (1999) fica destacada a importância do mundo vivido, em contraponto ao ascendente racionalismo. Tanto a experiência, quanto as formas de ser e estar com o outro, aparecem na obra do autor ao tratar da arte, da beleza, da questão do gosto, do juízo estético. As regras que definem o que é arte se fundamentam num padrão estabelecido socialmente que leva em conta o gosto, a beleza e a delicadeza. A delicadeza é tomada como uma capacidade sutil de perceber as mudanças das influências estéticas. Uma forma de perceber que precisa e deve ser lapidada com grande e constante esforço. A educação do gosto que se dá pela experiência prática de apreciação das formas de expressão de diferentes culturas.

O que Hume chama de delicadeza envolve tanto a capacidade corpórea de perceber o que é dado aos sentidos, como a forma pela qual essas experiências se articulam no contexto cultural em que os sujeitos estão inseridos. Dessa forma, opõe-se a uma universalidade do gosto, o que reafirma tanto o caráter subjetivo da experiência estética, como a consolidação de seu conteúdo por meio da cultura. No ensaio Of the Standard of Taste (1760), o autor repudiou a matriz filosófica responsável por imprimir uma linha divisória pronunciada e praticamente definitiva entre a construção teórica detentora de pretensas verdades de um lado

Divers@ Revista Eletrônica Interdisciplinar/Matinhos/Vol.5, n.1/p.1-92//jan./jun.2012 
e de outro, o sentimento ${ }^{4}$. Isso porque, para ele, o sentimento deve ser tomado como realidade, a partir do momento em que o homem tenha consciência dele (OSBORNE, 1968).

Ao mesmo tempo em que a racionalização das coisas do mundo foi se consolidando, também foi crescendo no campo da arte uma resposta à autoridade da razão e da regra. Termos como sentimento, imaginação, emoção, impressão e sensibilidade, no século XVIII, passaram a ser as palavras de ordem das novas tendências nesse meio. Tendências que se consolidaram com o Romantismo, influenciaram posteriormente a arte moderna, e tiveram o conceito de expressão como centro da ação poética. Essa leitura promoveu um enfrentamento em relação à passividade empirista, enfatizou o papel da imaginação, sobre ou em acréscimo à razão, bem como promoveu a distinção entre o útil e o belo. O que contribuiu para que se consolidasse a noção da arte como ação individual advinda da sensibilidade do artista como gênio criador e independente.

Nesse processo também ficou definido mais claramente o mercado das obras de arte como uma categoria particular de bens simbólicos. Devido ao surgimento desse mercado, segundo Bourdieu (2007), ocorreram profundas mudanças em relação às concepções sobre a arte, o estético e seu lugar na sociedade. De tal forma que o artista tornou-se afastado do público, ao mesmo tempo em que nascia um público anônimo de consumidores. Além disso, também destaca a aparição de métodos e técnicas tomadas de empréstimo à nova ordem econômica e ligados à comercialização da arte.

Nesse quadro foi delineado o processo de segmentação do campo artístico, que separa produção de bens simbólicos de acordo com o grau de distinção que é capaz de conceder para os seus fruidores. À medida que foi se consolidando a lógica da Indústria Cultural voltada para a conquista do maior mercado possível para os bens simbólicos de consumo de massa, o campo da arte foi se definindo como um sistema composto por um conjunto de indivíduos e instituições responsáveis pela produção, difusão e consumo de objetos e eventos por eles mesmos rotulados como artísticos.

Tal sistema, segundo Bourdieu (2007), obedece a uma lógica segundo a qual o reconhecimento cultural é concedido pelos grupos que dispõem de poder para definir as normas de produção e os critérios de avaliação dos produtos. Nesse sentido, há uma tendência cada vez maior de afastamento do público leigo, que dependeria de instrução, de manejo

4 Vale dizer ainda que Kant e Hume foram contemporâneos, o que possibilitou que as duas perspectivas se enfrentassem através dos próprios pensadores.

Divers@ Revista Eletrônica Interdisciplinar/Matinhos/Vol.5,n.1/p.1-92|/jan./jun.2012 
prático e teórico de códigos refinados, além é claro da disposição de adquiri-los para adentrar ao universo desse tipo de arte.

Vale destacar que nesse processo de segmentação do campo da arte, aqui entendido em suas mais variadas formas de expressão, as instâncias de conservação e consagração cultural, em especial o sistema de ensino cumpriu um importante papel na conversão e reprodução do que chamamos de erudito, em cultura legítima e superior. Dotando as ações educativas de esquemas pedagógicos, concepções e formas de abordagem para aproximar público e produção artística a partir de critérios que terminaram por gerar negação do valor estético das formas de expressão populares e tradicionais.

Os processos de autonomização e especialização dos campos científicos e estéticos, através da divisão intelectual e social do trabalho, representam características fundamentais da modernidade. A força da ciência colocada a serviço da vida prática e da compreensão dos mecanismos naturais permitiu a dessacralização da vida e da natureza. O que, por sua vez, possibilitou uma transformação impressionante na capacidade de organizar a vida material. Ao mesmo tempo, foi sendo realizada uma opção teórica, um caminho da verdade, um paradigma para o qual o pensamento kantiano tornou-se essencial.

O caminho da ciência apontou para a sistematização pragmática e para a exclusão dos elementos da transcendência e da dimensão sensível da pauta das reflexões consideradas cientificamente relevantes. Nesse contexto, o campo da arte ganhou espaço para diversificação dos processos de criação. Por um lado, o artista passou a ter uma liberdade maior, tanto na escolha dos temas, quanto das técnicas. De outro lado, a nova ordem social lhe obrigou a produzir em função da flexibilização do mercado e do prestígio social.

A definitiva autonomização do campo da arte consolidou a obra de arte como mercadoria e sua apreciação passou a ser responsabilidade de uma categoria particular de produtores de bens simbólicos. Segundo Gadamer (2005), os espaços como museus assumiram um papel importante na separação do trabalho artístico da vida cotidiana e ainda trouxeram uma dimensão de atemporalidade aos objetos da arte, reforçando a convicção de que a arte tem como única função provocar o prazer da fruição estética.

A perspectiva kantiana acabou sendo basilar para o estabelecimento dos fundamentos do pensamento ocidental. A partir de sua obra, é necessário que se diga que racionalismo e empirismo foram aliados, o que foi providencial para uma ciência capaz de proporcionar os instrumentais para o domínio da natureza, em prol do progresso material. Nesse sentido,

Divers@Revista Eletrônica Interdisciplinar/Matinhos/ Vol.5,n.1/p.1-92//jan./jun.2012 
através dele nasceu uma nova síntese filosófica. Síntese, que na "esteira do método moderno criado por Galileu, formatou o perfil para concretização dos parâmetros que definiram a modernidade e a maneira como encarar o conhecimento no processo de formação da sociedade ocidental" (DUARTE JÚNIOR, 2000, p.49). Perspectiva, segundo a qual, à ciência ficou reservado o conceito de verdade, enquanto para a arte foi negado um papel na construção do conhecimento humano.

Nas palavras de Duarte Junior

[...] a ciência promove descobertas, as máquinas seduzem, realizando tarefas, encurtando distâncias e promovendo o aumento da velocidade. A maioridade humana, célebre expressão dos iluministas, parece já bem próxima. E como emblema desse conjunto ideológico oitocentista, nada melhor que o positivismo elaborado por Augusto Comte e muito bem acolhido em diversos círculos letrados da época, já que uma filosofia que prega a superioridade da razão científica sobre todas as outras formas de conhecimento casa-se muito bem com esse abrangente progresso verificado ao derredor. Filósofos, cientistas, homens de negócio, militares e mesmo artistas creem estar muito próxima a idade da razão para toda a humanidade, idade em que sociedades plenamente racionalizadas deverão, por certo, promover um amplo bem-estar para os seus membros (2000, p.55).

A convicção na ciência e na racionalidade como portadoras das verdades adentrou o século XX. Tais verdades desenvolveram-se a partir da crença de que o homem contemporâneo estaria preocupado em situar-se e mover-se no mundo das coisas, possuí-las, usufruir delas, bem como impedir sua perda e não caberia nada que estivesse além da solução desses problemas enquanto meta do conhecimento científico. Todavia, foi o século XX o que mais explicitou as contradições da sociedade ocidental. Desta feita, foi ao longo dele que o pensamento ocidental foi alçado à busca de novos paradigmas, especialmente a partir do seu último quartel.

Depreende-se daí que a força do ideário moderno criou uma convicção de divisão, especialidade e precisão que continuam remetendo a arte a um papel secundário na formação humana. Sem dúvida, a crise da modernidade, que para muitas correntes de pensamento abriu um período de "pós-modernidade", e para outras representa seu aprofundamento, têm no mínimo um ponto de convergência. Essa, por sua vez, se expressa na explicitação dos limites da razão instrumental, o que requer um novo paradigma que reposicione as dimensões do intelectivo e do sensível na produção do conhecimento humano. Nessa perspectiva, por suas peculiaridades, à arte e à sua atuação na educação cabe um papel distinto daquele que conhecemos tradicionalmente.

Divers@ Revista Eletrônica Interdisciplinar/Matinhos/Vol.5, n.1/p.1-92|/jan./jun.2012 


\section{A importância da arte para a educação do homem}

É importante reiterar que já no contexto histórico do século XIX veio à tona o ceticismo em relação à ciência moderna. Conforme Lara (1986), autores como Nietzsche e Schopenhauer demonstraram esse ceticismo afirmando que "razão e experiência, ciência e técnica, ao invés de libertarem o homem, pareciam cadeias destinadas a subjugá-lo" (p. 93). Porém, nesse momento havia, de forma urgente, a necessidade de um sistema de pensamento que justificasse a nova ordem social e política.

Não podemos deixar de destacar, nesse contexto, ainda na passagem do século XVIII para o XIX, as contribuições de Friedrich Schiller (2002) sobre a educação estética do homem, tendo em vista as contribuições contemporâneas dela advindas. Em desacordo com as proposições que davam rumo à nova ordem sociocultural, Schiller apontou para a estética como intermediação possível para a educação e o aprimoramento ético da humanidade. Em uma série de cartas, ao todo 27 , refletiu sobre a educação estética, sobre a qualidade estética como responsável pela autodeterminação do homem.

Para Duarte Junior (2000, p.188), Schiller "traz a necessidade de serem desenvolvidas e educadas as duas dimensões por ele reconhecidas como básicas no ser humano: a racionalidade e a sensibilidade". A exemplo, Schiller escreveu em uma nota na Carta XX, parágrafo quarto,

[...] todas as coisas que de algum modo possam ocorrer no fenômeno são pensáveis sob quatro relações diferentes. Uma coisa pode referir-se imediatamente a nosso estado sensível (nossa existência e bem-estar); esta é sua índole física. Ela pode, também, referir-se a nosso entendimento, possibilitando-nos conhecimento: esta é sua índole lógica. Ela pode ainda referir-se a nossa vontade e ser considerada como objeto de escolha para um ser racional: esta é sua índole moral. Ou, finalmente, ela pode referir-se ao todo de nossas diversas faculdades sem ser objeto determinado para nenhuma isolada entre elas: esta é sua índole estética. Um homem pode ser-nos agradável por sua solicitude; pode, pelo diálogo dar-nos o que pensar, pode incutir respeito pelo seu caráter; enfim, independentemente de tudo e sem que tomemos em consideração alguma lei ou fim, ele pode aprazer-nos na mera contemplação e apenas por seu modo de aparecer. Nessa última qualidade julgamo-lo esteticamente. Existe, assim, uma educação para a saúde, uma educação do pensamento, uma educação para a moralidade, uma educação para o gosto e a beleza (SCHILLER, 2002, p. 103).

As palavras do autor também apontam para uma perspectiva na qual é no domínio do estético que as faculdades humanas alcançam sua integralidade. Nesse sentido, traz a concepção de uma razão mais abrangente, na qual o sensível e o racional devem estar colocados em relação de equilíbrio. Também tinha a clara percepção de um momento

Divers@ Revista Eletrônica Interdisciplinar/Matinhos/ Vol.5, n.1/p.1-92//jan./jun.2012 
histórico em que arte e ciência, razão e sensibilidade estavam assumindo uma condição de oposição na vida prática e na educação do homem. A utilidade escreveu Schiller,

[...] é o grande ídolo da época; ela exige que todas as forças lhe sejam submetidas e que todos os talentos lhe prestem homenagem', concluindo que o mérito espiritual da arte é um tanto irrisório em meio à quermesse ruidosa do século (SCHILLER, 2002, p.81).

Assim, podemos dizer que, se para Kant a beleza está relacionada à ação teórica e a arte aparece como processo sem finalidade, para Schiller a arte educa porque é nela que experimentamos a liberdade. Em sua obra a educação estética tem por finalidade a busca do equilíbrio entre intelectivo e sensível, contudo não se encerra nela. Para ele, tratava-se de enfrentar as graves consequências da ascendente hegemonia da mentalidade mercantilista e utilitarista que assolava as relações sociais do seu tempo.

Segundo Habermas (2002), Schiller concebe a arte como uma razão comunicativa que traz um sentido comunitário e é mediadora de uma razão que anula a oposição entre natureza e liberdade, pois provoca uma intermediação na qual a mente se faz ativa tanto física quanto moralmente. O que se destaca na interpretação de Habermas, se refere ao fato de que Schiller teria apontado na arte o elemento unificador moral. "No lugar da religião deve ser a arte que pode ser ativa enquanto poder unificador porque ela é entendida como uma forma de transmissão que intervém nas relações subjetivas dos homens" (p.51).

Nesse sentido, se tomarmos a educação e a arte como elementos do humano que se fundem em prol da liberdade, seu objetivo passa a ser simultaneamente desenvolver a singularidade, a individualidade e a sua consciência social, tomada como "reciprocidade do indivíduo" (READ, 2007, p. 18). Dessa forma como afirma Duarte (1998, p.134) "a arte é um elemento fundamental para que, expressando suas vivências, o educando possa chegar a compreendê-la e a emprestar significados à sua condição no contexto cultural”. Herbert Read (1986) também argumentou em prol da necessidade de uma educação estética, uma educação artística como base para os processos que envolvem a formação das paisagens subjetivas em sua relação com o mundo exterior, voltada para a construção da personalidade integrada dos sujeitos.

Em que pese tal essencialidade da arte na vida dos sujeitos, sobretudo a partir de sua vinculação com os aspectos cotidianos que perpassam as experiências humanas, observamos uma espécie de subjugação de seu papel na educação. É preciso que se diga, no entanto, que são várias as iniciativas e reflexões relacionadas ao ensino e aprendizagem da arte

Divers@Revista Eletrônica Interdisciplinar/Matinhos/ Vol.5,n.1/p.1-92//jan./jun.2012 
preocupadas em estabelecer uma relação adequada entre teoria e prática, estreitando as interfaces entre arte e vida. Apontam para a necessidade de criar condições de aprendizagem que despertem nos sujeitos a capacidade de questionar a realidade a partir dos processos que envolvem o sentir, o pensar e o dar forma aos seus anseios, a partir da atividade criadora. $\mathrm{Ou}$ como afirma Machado:

Penso que se trata, antes de qualquer coisa, de acordar a percepção. Perceber é distinguir qualidades. Porque qualificar é entrar em contato com o que dá sentido, essencialmente a tudo que existe (2011, p. 25).

Vale dizer, que nesses termos é adequado pensar no conceito de educação como formação, como processo de crescimento, como aponta Read (1986). Inclusive porque a educação formal é apenas parte de um processo maior e está contida no processo de formação que se dá na multiplicidade de espaços e sistemas culturais com e nos quais os sujeitos em processo de formação convivem e interagem.

\section{Apontamentos Finais}

O paradigma moderno trouxe certezas construídas sob a negação da dimensão sensível para educação do homem e relegou à arte um papel secundário no processo de formação dos sujeitos. Em contraponto, é no emaranhado de desafios educativos que são colocados no contemporâneo, sobretudo, para os que trabalham com crianças e adolescentes, que compreendemos a relevância do papel da arte, do fazer artístico (expressão poética) e da experiência estética, bem como suas possibilidades de conduzir os sujeitos à interação com conteúdos de sua própria cultura.

Somos corpo e alma, razão e sentimento, mas também estamos no tempo e no espaço e é exatamente a interação dessa complexidade humana que acreditamos ser possibilitadora de uma alquimia do aprendizado. O que nos guia nessa busca de construção dos significados, e da compreensão do papel da arte para o conhecimento humano, é o entendimento de que pobreza não se traduz apenas na ausência de bens materiais ou de alimentos, mas também na expropriação das capacidades cognitivas, perceptivas e criadoras do homem.

Parece-nos essencial destacar que no contexto contemporâneo, as situações de aprendizagem em arte, podem e devem nos convocar a andar por caminhos inesperados, de descobertas, e nos abrir as portas para rompermos com o desencantamento do mundo herdado

Divers@Revista Eletrônica Interdisciplinar/Matinhos/ Vol.5,n.1/p.1-92//jan./jun.2012 
das proposições modernas. Dessa forma, nos faz perceber tais situações devem primar por criar condições de aprendizagem que promovam a ruptura com a habitualidade do pensar e do sentir. Afinal, como destaca Dewey (2010, p.114): "nenhuma experiência poderá constituir-se numa unidade, a menos que apresente qualidade estética. (...) Os inimigos do estético são o monótono, a submissão à convenção nos procedimentos práticos e intelectuais".

Dessa forma, a importância da arte para educação está no fato de que proporciona uma experiência na qual a ação poética e a recepção estética se articulam como eixos dos processos educativos, contribuindo para a formação do gosto artístico e estético, para a educação da percepção. Um alimento para formação de juízos e valores imprescindíveis para que o sujeito em processo de formação dote significados à sua condição cultural.

\section{Referências}

ABRÃO, Bernadette Siqueira. História da filosofia. São Paulo: Nova Cultural, 1999.

BOURDIEU, Pierre. Economia das trocas simbólicas. São Paulo: Perspectiva, 2007.

DEWEY, John. Arte como experiência. São Paulo: Martins Fontes, 2010.

DUARTE, JÚNIOR. Fundamentos estéticos da educação. Campinas/SP: Papirus, 1998.

O Sentido dos sentidos: a educação do sensível. (Doutorado em Filosofía da Educação) Faculdade de Educação. Universidade Estadual de Campinas. Campinas, 2000.

GADAMER, Hans-George. Verdade e método - Traços fundamentais de uma hermenêutica filosófica. Ed. Vozes: Petrópolis, RJ, 2005.

HABERMAS, Jurgen. O discurso filosófico da modernidade: Doze Lições. Tradução Luiz Sérgio Repa e Rodnei Nascimento. São Paulo: Martins Fontes, 2002.

HUME, David. Investigação acerca do entendimento humano. (1777). Tradução Anoar Aiex. In: Hume - Os Pensadores. São Paulo: Nova Cultural Ltda. 1999. Série Os Pensadores

KANT, Immanuel. Crítica da faculdade do juízo. Tradução de Valério Rohden e António Marques. Rio de Janeiro, RJ: Forense Universitária, 1993.

LARA, Tiago Adão. Caminhos da razão no ocidente - A filosofia ocidental do renascimento aos nossos dias. Rio de Janeiro: Vozes. 1986. 
MACHADO, Regina. Venha ver o pôr do sol: considerações sobre a experiência do silêncio na formação artística. IN: ROIPHE, Alberto; MATTAR, Sumaya. Processos de criação na educação e nas artes. São Paulo: ECA-USP, 2012.

NUNES, Benedito. Introdução a filosofia da arte. São Paulo: Ática, 1999.

OSBORNE, Harold. Estética e teoria da arte - Uma introdução histórica. São Paulo: Cultrix, 1968.

READ, Herbert. Educação pela arte. Lisboa: Edições 70, 2007.

A redenção do robô - meu encontro com a educação através da arte. São Paulo: Summus, 1986.

RICHTER, Sandra. Bachelard e a experiência poética como dimensão educativa da arte. IN: Revista Educação, Santa Maria, v.31, n.02, p. 241-254, 2006. Disponível em http:///www.ufsm.br/ce/revista>, Acessado em abril de 2012.

SANTOS, Manoel Ferreira dos. Dicionário de filosofia e ciências culturais. São Paulo: Matese, 1962.

SCHILLER, Friedrich. A educação estética do homem. Uma série de cartas. Tradução: Roberto Schwarz. Editora Iluminuras: São Paulo, 2002.

ZATTI, Vicente. Autonomia e educação em Immanuel Kant e Paulo Freire. Porto Alegre. EDIPUCRS, 2007. 